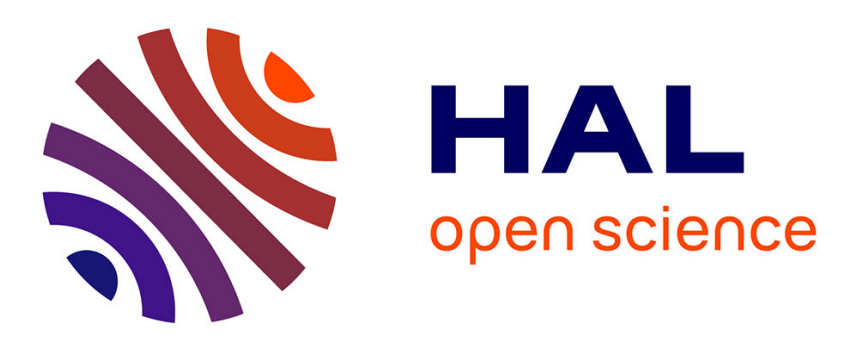

\title{
The solute mechanical properties impact on the drying of dairy and model colloidal systems
}

Cécile Le Floch-Fouéré, Luca Lanotte, Romain Jeantet, Ludovic Pauchard

\section{To cite this version:}

Cécile Le Floch-Fouéré, Luca Lanotte, Romain Jeantet, Ludovic Pauchard. The solute mechanical properties impact on the drying of dairy and model colloidal systems. Soft Matter, 2019, 10.1039/C9SM00373H . hal-02284136

HAL Id: hal-02284136

https://institut-agro-rennes-angers.hal.science/hal-02284136

Submitted on 11 Mar 2020

HAL is a multi-disciplinary open access archive for the deposit and dissemination of scientific research documents, whether they are published or not. The documents may come from teaching and research institutions in France or abroad, or from public or private research centers.
L'archive ouverte pluridisciplinaire HAL, est destinée au dépôt et à la diffusion de documents scientifiques de niveau recherche, publiés ou non, émanant des établissements d'enseignement et de recherche français ou étrangers, des laboratoires publics ou privés. 


\section{Soft}

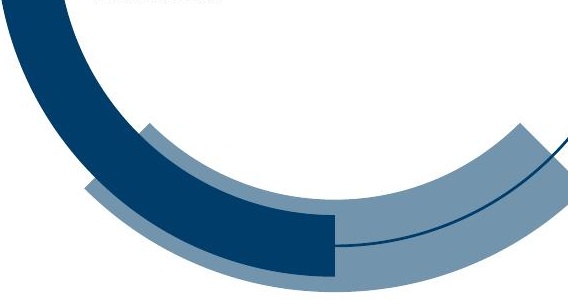

\section{Accepted Manuscript}

This article can be cited before page numbers have been issued, to do this please use: C. Le Floch-

Fouéré, L. Lanotte, R. Jeantet and L. Pauchard, Soft Matter, 2019, DOI: 10.1039/C9SM00373H.
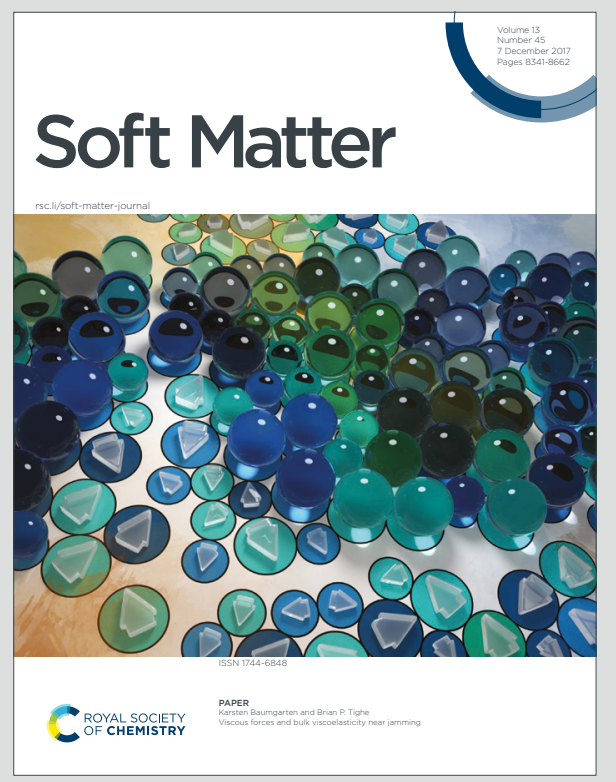

This is an Accepted Manuscript, which has been through the Royal Society of Chemistry peer review process and has been accepted for publication.

Accepted Manuscripts are published online shortly after acceptance, before technical editing, formatting and proof reading. Using this free service, authors can make their results available to the community, in citable form, before we publish the edited article. We will replace this Accepted Manuscript with the edited and formatted Advance Article as soon as it is available.

You can find more information about Accepted Manuscripts in the Information for Authors.

Please note that technical editing may introduce minor changes to the text and/or graphics, which may alter content. The journal's standard Terms \& Conditions and the Ethical guidelines still apply. In no event shall the Royal Society of Chemistry be held responsible for any errors or omissions in this Accepted Manuscript or any consequences arising from the use of any information it contains. 


\title{
Journal Name
}

\section{Solute mechanical properties impact on the drying of dairy and model colloidal systems}

Received 00th January 20xx, Accepted 00th January 20xx

DOI: $10.1039 / \times 0 x \times 00000 x$

www.rsc.org/

\author{
Cécile Le Floch-Fouéré, ${ }^{* a}$ Luca Lanotte, ${ }^{a}$ Romain Jeantet ${ }^{\mathrm{a}}$ and Ludovic Pauchard ${ }^{\mathrm{b}}$
}

\begin{abstract}
The evaporation of colloidal solutions is frequently observed in nature and in everyday life. The investigation of the mechanisms taking place during the desiccation of biological fluids is currently a scientific challenge with potential biomedical and industrial applications. In last decades, seminal works have been performed mostly on dried droplets of saliva, urine and plasma. However, the full understanding of the drying process in biocolloids is far to be achieved and, notably, the impact of solute properties on the morphological characteristics of the evaporating droplets, such as colloid segregation, skin formation and crack pattern development, is still to be elucidated. To this purpose, the use of model colloidal solutions, whose rheological behavior is more easily deducible, could represent a significant boost. In this work, we compare the drying of droplets of whey proteins and casein micelles, the two main milk protein classes, to that of dispersions of silica particles and polymer-coated silica particles, respectively. The mechanical behavior of such biological colloids and model silica dispersions was investigated through the analysis of crack formation, and the measurements of their mechanical properties using indentation testing. The study reveals numerous analogies between dairy and corresponding model systems, thus confirming the latter as plausible powerful tool to highlight the signature of the matter at the molecular scale on the drying process.
\end{abstract}

\section{Introduction}

The evaporation of a droplet, whether free falling in the air or deposited on a substrate, has been extensively studied in the past decades in the frame of numerous experimental works on both solutions and dispersions ${ }^{1-9}$. Several coupled phenomena are involved in the drying process of drops containing solutes. The evaporation of the solvent takes place at the air-liquid interface, where in return the non-volatile components concentrate selectively ${ }^{10}$. Such a local increase of solute at the surface results in concentration gradients fostering transport and diffusive phenomena through the drop. The progress of the evaporation causes the solute phase to be confined into an inexorably smaller volume until forming a dense network that withstands an increasing compression. Indeed, when the drying process is significantly advanced, the air-liquid interface curves into a set of menisci joining the solid particles and exerts compressive stresses induced by capillary forces ${ }^{11}$. On the contrary, the pinning of the sample to the substrate tends to limit the shrinkage of droplet borders. These competitive actions lead to the development of a mechanical tension that is finally released by the occurrence of cracks ${ }^{12}$.

\footnotetext{
a. Laboratoire STLO, UMR1253, INRA, Agrocampus Ouest, F-35000 Rennes, France. b. Laboratoire FAST, Univ. Paris-Sud, CNRS, Université Paris-Saclay, F-91405 Orsay, France.

+ Footnotes relating to the title and/or authors should appear here.

Electronic Supplementary Information (ESI) available: [details of any supplementary information available should be included here]. See DOI: 10.1039/x0xx00000x
}

The evaporation stages and the resulting crack patterns constitute a sort of signature of the material, as it has been shown for ferrofluid ${ }^{13}$ or anisotropic particles ${ }^{14}$ for example.

Regarding the study of fracture occurrence in drying droplets, the investigation of biological fluids has recently attracted an increasing interest because of possible biomedical, forensic, archaeological and industrial applications. For example, the observation of the final crack pattern in dried droplets of biological fluids (saliva, urine, plasma) ${ }^{15-17}$ and suspensions (blood) ${ }^{18-21}$ has been used to detect pathological states and develop innovative diagnostic methodologies. The study of the evaporation of biological suspensions represents a scientific challenge due to the high complexity of the system, which is essentially composed by deformable objects (cells) dispersed in an aqueous fluid rich in proteins and salts. At the end of the process, the samples display complex patterns of cracks, whose morphology strongly depends on cell mechanical characteristics and size and on the physico-chemical properties of the suspending fluid ${ }^{22-25}$. However, although the advances of the last decades, underlined by recent reviews containing biological applications ${ }^{26-30}$, the full understanding of the rich variety of mechanisms (e.g. physico-chemical, mechanical) occurring throughout the dehydration of biological dispersions is far to be achieved. To simplify the scientific contest to investigate, a significant part of the studies has been focused on biological solutions rather than suspensions. In particular, considerable progress has been made to elucidate the drying process in solutions of biocolloids. 
For instance, some of our previous works ${ }^{31-33}$ dealt with the drying of the two main milk protein classes, i.e. whey proteins (observed in form of isolates, WPI) and casein micelles (observed in form of native phosphocaseinates, NPC), using both spray and single droplet approach. Whey proteins have a compact globular structure characterized by a well-defined folding of polypeptide chains. In bovine milk, they are composed by $\approx 70 \% \beta$-lactoglobulin (dimer molecular mass of $36.6 \mathrm{kDa}$ ) and $\approx 20 \% \alpha$-lactalbumin (molecular mass $14.2 \mathrm{kDa}$ ). ${ }^{34}$ Casein micelles represent a complex association of caseins ( $\alpha$ s1, as2-, $\beta$ - and K-caseins), phosphate and calcium ions organized into a micellar assembly whose internal structure has been a matter of controversy for decades ${ }^{35-40}$. Both experimental approaches highlighted that the drying of WPI and NPC under controlled experimental conditions leads to two clearly noticeable types of morphology: dense, wrinkled particles for NPC and hollow, spherical particles for WPI. ${ }^{33,41}$ These specific shapes result from the occurrence of distinct types of surface instabilities during the desiccation. Such selective behaviors suggested that casein micelles could behave like soft colloids, thus conferring a ductile character to the dried samples. On the other hand, whey proteins are plausibly similar to rigid spheres and provide a plastic brittle character to the dried particles.

In the light of this preliminary interpretation, the goal of this study is to evaluate the impact of the mechanical properties of WPI and NPC in concentrated phase on the drying of droplets by using solutions of model colloids with similar structural properties. In particular, silica nanoparticles were used to simulate stiff WPI macromolecules and polymer-coated nanospheres to mimic the behavior of soft NPC micelles. The mechanical behaviors of biological colloids and model colloidal dispersions were investigated through i) the analysis of crack formation, and ii) the measurement of their mechanical properties using indentation testing. Since the model colloids can be more easily characterized, comparing the drying of dairy and associated model systems contributes to better understand the physical mechanisms taking place throughout the evaporation of droplets of milk colloids. The outcomes presented in this work represent a first step to shed light on the physics of drying dairy droplets and they open the road to further investigation about mixes of milk proteins. Moreover, the observation of mixtures of dairy colloids would contribute to improve the knowledge about the evaporation of colloidal polydisperse systems, which represents a current scientific challenge.

\section{Experimental}

\section{Materials}

\section{Solutions of WPI and NPC proteins}

Biological solutions of whey protein isolates (WPI) and native phosphocaseinates (NPC) were prepared with powders obtained from industrial sources and presenting $\mathrm{a}_{\mathrm{art}}$ Protein

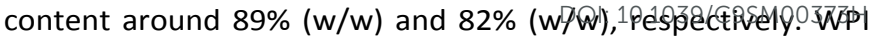
and NPC powders were separately dispersed up to a concentration $\approx 10 \%(\mathrm{v} / \mathrm{v})$ in reverse osmosis water containing $0.02 \%(\mathrm{w} / \mathrm{w})$ of sodium azide acting as bacteriostatic agent. The samples underwent continuous stirring overnight at $35^{\circ} \mathrm{C}$ to ensure full dissolution. The diameter distribution of dissolved proteins was measured by dynamic light scattering using a Zetasizer NanoZS apparatus (Malvern Instruments, Malvern, UK): from 8 to $30 \mathrm{~nm}$ for WPI and from 108 to $300 \mathrm{~nm}$ for NPC proteins. At $20^{\circ} \mathrm{C}$, the $\mathrm{pH}$ of the two dispersions matched the average $\mathrm{pH}$ of milk, i.e., $6.6 \pm 0.2$.

\section{Model colloidal dispersions}

An aqueous dispersion of silica colloidal particles (Ludox ${ }^{\circledR}$ TM50, Sigma-Aldrich) was used as colloidal model system of the biological solutions of WPI. TM50 suspensions are commercially provided with volume fraction of $20 \%$ and $p H=9.2$. The particles exhibit a mean diameter $a=22 \mathrm{~nm} \pm 2 \mathrm{~nm}$ and their surface bear a high negative charge density. ${ }^{42}$ In the absence of evaporation or any other external agent, the colloidal dispersion is stable due to the electrostatic repulsion between TM50 particles. The particle volume fraction of the dispersion was adjusted to $15 \%$ by adding pure distilled water.

A second enhanced colloidal system, mainly consisting of a polymer layer grafted on TM50 surface, was used to simulate the behavior of NPC solutions. The adsorption on silica surfaces of organic molecules, such as Polyethylene Oxide (PEO) and PolyVinylPyrrolidone (PVP), has been largely characterized in the literature ${ }^{43}$ especially for Polyethylene Oxide (PEO) ${ }^{44-47}$ and PVP ${ }^{48-53}$. In this case, PolyVinylPyrrolidone (PVP, molar mass of $40 \mathrm{kDa}$, Sigma Aldrich) was chosen due to its high affinity for silica surfaces. ${ }^{43,50}$ PVP was preliminarily dissolved in pure water at $p H=9.2$ with a weight concentration $\left(c_{p}\right)$ ranging from $0 \%$ $(w / w)$ to $0.3 \%(w / w)$. Afterwards, this solution was used to dilute the commercial Ludox ${ }^{\circledR}$ TM50 suspension up to a final volume concentration of $15 \%$, in analogy with pure TM50 system.

\section{Methods}

\section{Observation of sessile droplet evaporation}

The experiments consisted in observing the drying of sessile droplets of both biological and model samples (volume equal to $3.0 \pm 0.5 \mu \mathrm{l}$ ) carefully deposited on clean glass slides using the protocol already described in previous works. ${ }^{54}$ All tests were performed at controlled temperature $\left(T=22 \pm 2^{\circ} \mathrm{C}\right)$ and relative humidity $(R H=40 \pm 2 \%)$. The morphological evolution of the sessile droplets during the evaporation was observed in top view using a Pxelink camera with a $60 \mathrm{~mm}$ lens macro and images were regularly acquired for off-line analysis. Sessile drops of biological solutions and associated model systems showed comparable contact angles: $31 \pm 2^{\circ}$ for both WPI and TM50 colloidal dispersion and $35 \pm 2^{\circ}$ for both NPC and 
TM50+PVP colloidal dispersion. The tight control of key parameters such as sample solid volume fraction and initial contact angle ensured to obtain similar characteristic lengths (e.g. drop diameter and/or height) in the different systems during the drying process. Since the surface tension dominates on gravitational effects, the sessile droplets exhibited spherical cap shapes. During water evaporation, the particles tended to deposit on the substrate, resulting in a strong anchoring of the three-phase line. The edge pinning persisted throughout all the drying due to the high concentration of the samples, and a constant base diameter $R_{0}=4 \mathrm{~mm}$ was measured. The evaporation rate was estimated to be $8^{*} 10^{-8} \mathrm{~m}^{*} \mathrm{~s}^{-1}$ taking into account the impact of droplet geometrical characteristics and relative humidity, $R H$.

\section{Indentation measurements on flat layers of biological and colloidal solutions}

The mechanical properties of the concentrated phases of biological colloids and model systems were estimated using indentation testing (CSM Instruments Micro Indentation Tester, $\mathrm{MHT}$ ) with a spherical indenter tip of radius $r=0.25 \mathrm{~mm} .{ }^{55}$ This method was carried out through creep measurements on different flat layers $(\approx 200 \mu \mathrm{m}$ thick) strongly adhering on a glass slide. The measurement starts at time $t=0$, that is approximately 2 minutes after the formation of the crack pattern in the layer. Hence, the concentrated phase still consists of a network of colloids whose interstices are filled with water. Then the spherical indenter tip initially in contact with the surface of the gel, penetrates the sample with a controlled loading speed $\left(500 \mathrm{mN}^{*} \mathrm{~min}^{-1}\right)$ until reaching a maximal force $F_{m}$ at time $t_{0}$ (Fig. 1). The maximum force $F_{m}$ is then held on the layer, and the change in penetration depth is measured as a

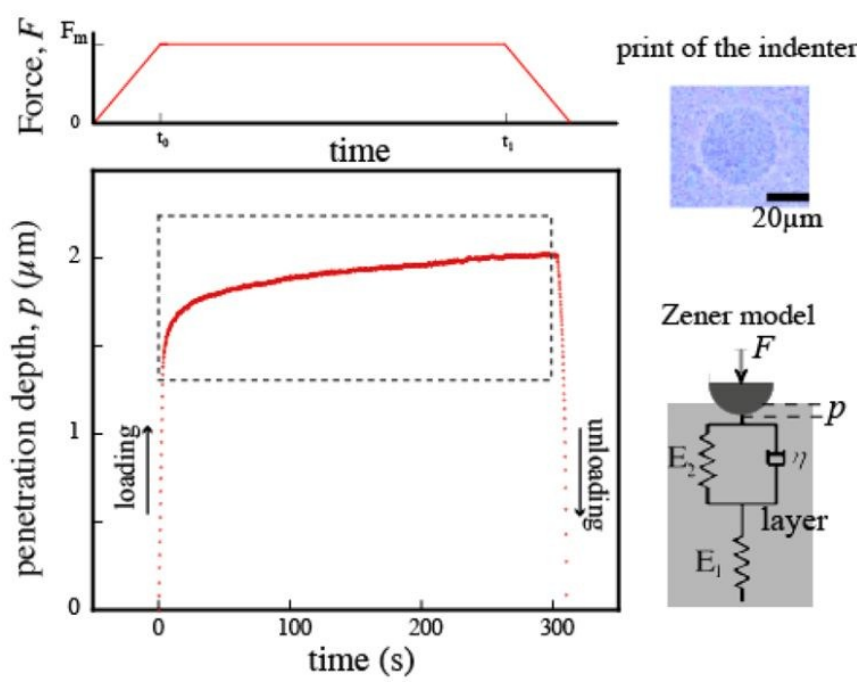

Fig. 1: Time variation of the penetration depth using indentation testing during the interval $t_{1}-t_{0}$ (red dots). The dashed frame points out the creep measurements performed at constant applied force $\mathrm{F}_{\mathrm{m}}$. On the right: up) top view of the print at the surface of the layer after removing the spherical indenter; bottom) the rheological behavior of the layer is characterized by a rheological 'Zener' model where a spring is connected in series with a combination of spring and dashpot. function of time. After a delay time, the applied $d_{A \text { f force }}$ iris

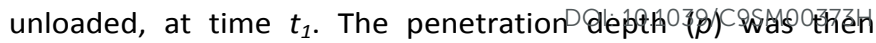
measured as a function of time during $t_{1}-t_{0}=300 \mathrm{~s}$ (note that the largest penetration depth of the indenter inside the layer applied here, $\approx 2 \mu \mathrm{m}$, is much lower than the thickness of the dried layers). A linear viscoelastic model (Zener model) was then used to quantify the experimental results. The Zener model can be represented as a spring of elastic modulus, $E_{1}$, connected in series to a purely viscous damper, $\eta$, and purely elastic spring, $E_{2}$, connected in parallel. Hence, the response to an external constant force, $F_{m}$, was expressed as: 56

$$
p^{\frac{3}{2}}(t)=\frac{3}{4 \sqrt{r}} F_{m}\left(\frac{1}{E_{1}}+\frac{1}{E_{2}}\left(1-e^{-\frac{t-t_{0}}{t_{v e}}}\right)\right)
$$

Where the viscoelastic timescale, $t_{v e}$ defined as the ratio between the viscosity $\eta$ and the elastic modulus $E_{2}$.

\section{Results and discussion}

\section{Drying process of the sessile droplets}

A preliminary experimental phase was devoted to the investigation of the polymer concentration influence on TM50+PVP droplet shape during the evaporation. The goal was to optimize the PVP amount and to obtain a similar mechanical behavior compared to NPC drying samples. PVP is a non-ionic and water-soluble macromolecular compound, which is known for its properties of emulsification and cohesiveness. It is often used to enhance the dissolution of various solid dispersions ${ }^{57-60}$ and to obtain nanoparticles with controlled chemical and structural characteristics ${ }^{61}$. It has been observed that, once PVP and nanospheres are mixed together, polymer chains tend to line particle surfaces without affecting suspension stability, until reaching a critical concentration (amount of PVP per available particle surface, $1 \mathrm{mg}^{*} \mathrm{~m}^{-2}$ ) that induces sudden flocculation ${ }^{48}$. In dilute conditions (PVP concentration lower than critical one), Cohen Stuart et al. ${ }^{52}$ showed that the typical conformation of PVP molecular chains consists of a sequence of many short loops and trains. Since the PVP concentration used in this work does not exceed $0.01 \mathrm{mg}^{*} \mathrm{~m}^{-2}$, it is plausible to hypothesize a similar polymer structure and a polymer-coated suspension free of significant aggregate amount ${ }^{50}$. 


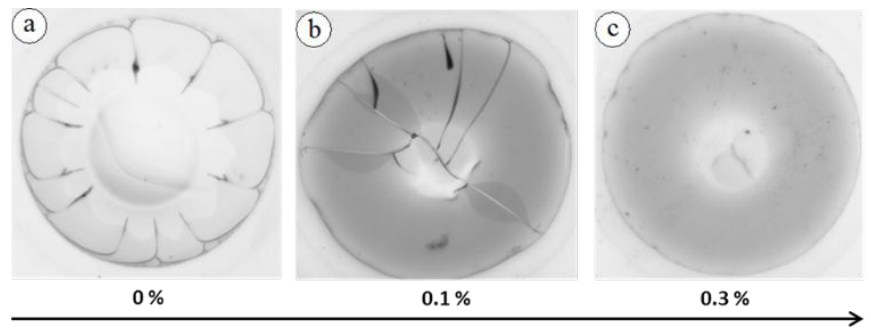

Initial weight concentration of polymers $\mathrm{Cp}$

Fig. 2: Dry sessile drops of Ludox ${ }^{\circledast}$ TM50 particles coated with PVP in water at different weight fraction $c_{p}$ (volume fraction $\approx 15 \%$ and $\mathrm{R}_{0}=4 \mathrm{~mm}$ ); (a) $c_{p}=0$ : radial cracks in the solid rim form during the drying process. (b) $c_{p}=0.1 \%$ : crack pattern formed at the final stage of the drying. (c) $c_{p}=0.3 \%$ : crack-free drop at the final stage of the drying.

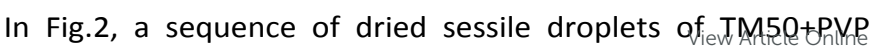
samples with different PVP weight concehtratiohple displaped? lt is well established that samples of pure Ludox ${ }^{\circledR} \mathrm{TM} 50$ after evaporation are characterized by a pattern of cracks typical of brittle materials (Fig.2a) ${ }^{62}$. However, the addition of polymer (PVP, mainly on particle surface but partially in the solution too) showed to affect the dynamics of crack development (Fig.2b) until the complete inhibition of crack formation above a critical content (Fig.2c). The systematic decrease of crack patterns induced by the addition of polymers in colloidal dispersions has been observed throughout the drying process in different systems. For example, Zhang et al. ${ }^{63}$ and Boulogne et al. ${ }^{50}$ observed this phenomenon in colloidal droplets with PEO addition. Interestingly, Boulogne et al. ${ }^{50}$ investigated the airliquid interface in drying films of silica colloidal dispersions analogous to those used in this work with addition of PVP (40 $\mathrm{kDa}$ ). They noticed the suppression of surface instabilities for an initial weight concentration of polymers equal to $0.33 \%$ that is comparable to the maximum amount used for our experiments $(c p=0.3 \%)$. The suppression of instabilities and cracks was
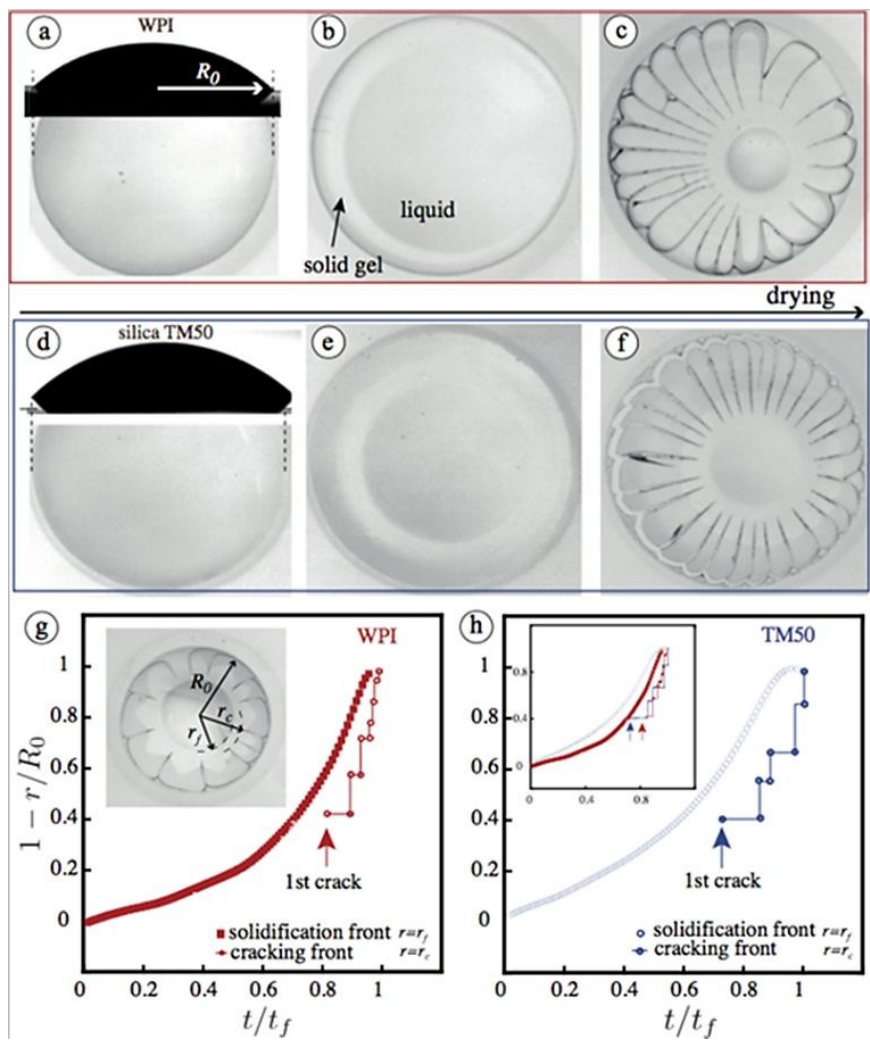

Fig. 3: Drying process of sessile drops of WPI solution and associated model system $\left(R_{0}\right.$ $=4 \mathrm{~mm}) .(\mathrm{a}, \mathrm{b}, \mathrm{c})$ Morphological evolution with time of sessile drops of a WPI solution $\left(t_{f}\right.$ $=820 \mathrm{~s}$ ). (a) Spherical cap shape in side and top view just after the deposition onto the substrate. (b) Top view of the gelled "foot" at $0.2 * t_{f}$. (c) Top view of the radial cracks pattern at $0.9 * t_{f .}(\mathrm{d}, \mathrm{e}, \mathrm{f})$ Sessile drop of a silica TM50 dispersion $\left(t_{f}=770 \mathrm{~s}\right)$. (d) Spherical cap shape in side and top view just after the deposition onto the substrate. (e) Top view of the gelled "foot" at $0.2 * t_{f}$. (f) Top view of the radial cracks pattern at $0.9 * t_{f}$. Time variations of both the solidification front and the cracking font, defined as a line connecting the crack tips, in the case of sessile drops of (g) WPI and model system (h) (inset: superposition of the fronts evolution).

related to the increase of the material elastic modulus. Finally, 
similar results have been observed in drying suspensions of soft nanolatex spheres ${ }^{64}$. In this case, the authors suggested that the presence of soft particles affects the release of internal stresses due to their deformability.

In the light of these considerations and due to the evident similarity of dry TM50+PVP drops with NPC samples (a qualitative comparison will be presented in the following results), for the rest of the present study the initial weight concentration of PVP will be equal to $0.1 \%$.

\section{Propagation of the solidification front}

In order to do this, the morphological evolution with time of droplets of both dairy and model systems was recorded to point out eventual similarities or differences during the drying process (WPI and TM50 in Fig.3 and NPC and TM50+PVP in Fig.4). The evaporation of sessile colloidal droplets usually results into large concentration and chemical gradients and the propagation of two drying fronts: 65

i) A vertical drying front perpendicular to the substrate (vertical front), leading to the formation of the skin at the air-liquid interface; ${ }^{32}$

ii) A centripetal solidification front parallel to the substrate plane (horizontal front) that delimits the transition area between liquid and solidifying phase.

Under our fixed experimental conditions (temperature, relative humidity and initial droplet contact angles), the centripetal drying was much faster than the vertical one. The internal flows were directed from the center towards drop edges advecting the non-volatile compounds. Therefore, the formation of a
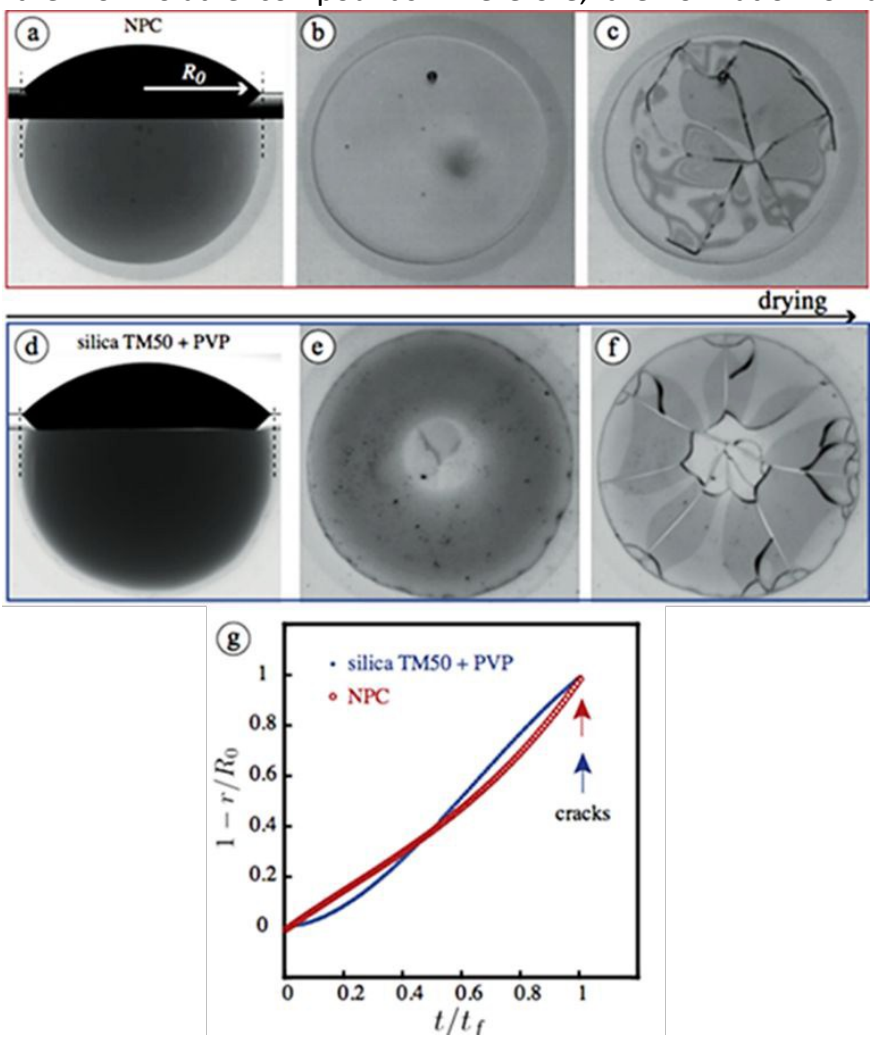

Fig. 4: Drying process of sessile drops of NPC solution and associated model system $\left(R_{0}=\right.$ $4 \mathrm{~mm}$ ). (a, b, c) Sessile drop of a NPC solution $\left(t_{f}=920 \mathrm{~s}\right)$. (a) Spherical cap shape in side and top view just after the deposition onto the substrate. (b) Top view taken at advanced solidification of the sessile drop at $0.9 * t_{\mathrm{f} .}$ (c) Top view of the crack pattern at $t_{f .}(\mathrm{d}, \mathrm{e}, \mathrm{f})$ Sessile drop of a silica TM50+PVP dispersion $\left(t_{f}=880 \mathrm{~s}\right)$. (d) Spherical cap shape in side and top view just after the deposition onto the substrate. (e) Top view taken at almost completed solidification of the sessile drop at $0.9 * t_{f}$. (f) Top view of the crack pattern at $t_{f}$. $(g)$ Time variations of both the solidification front and the crack font in the case of sessile drops of NPC and modeled system. (h) Dimensionless profiles of drops recorded and superposed at different times for a NPC sessile drop. gelled rim at droplet periphery was observed in all, the samples

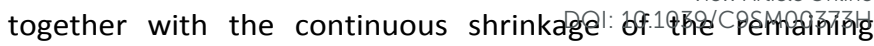
water. ${ }^{62}$ As it concerns WPI and TM50 samples, a solidification front between the wet gel and the liquid phase is clearly detectable as a line dividing the two different refractive media, as illustrated in Fig.3b (WPI) and Fig.3e (TM50). On the other hand, beyond mere optical reasons due to the turbidity induced by the light scattering of casein micellar structures, the presence of the horizontal front results less evident in NPC drying solutions (Fig.4b). Interestingly, a similar behavior is observed in the TM50+PVP associated model system (Fig.4e).

The time variation of the solidification front location was quantitatively evaluated for sessile drops of WPI (Fig.3g) and NPC solutions (Fig.4g). The same analysis was carried out on TM50 (Fig.3h) and TM50+PVP droplets (Fig.4g) where $r$ is the radial coordinate, $r_{f}$ is the position of the solidification front and $r_{c}$ is the position of the position of the cracking front. The plots resulting from this systematic analysis refer to a dimensionless time $t / t_{f}$, where $t_{f}$ is an extrapolated time estimated as the time necessary for the solidification front to reach the center of the sessile droplet. ${ }^{66}$ Such a parameter strictly depends on the solute volume fraction of the initial solution, the particle volume fraction of the dried material and the timescale related to the complete evaporation of a pure water drop in the same experimental conditions. The curves regarding whey proteins (Fig.3g) and casein micelles (Fig.4g) display a consistent agreement with those of their associate model systems, shown in Fig. $3 \mathrm{~h}$ and Fig.4g, respectively. In fact, for both WPI and TM50 droplets, the solidification front displays a linear displacement with time until $t \approx 0.6 t_{f}$. Afterwards, the last part of the evaporation process is characterized by an increase of the front velocity underlined by a change of the curve slope. On the other hand, as it concerns NPC and TM50+PVP drops, the horizontal front propagation is almost linear until the complete solidification.

Such a different behavior can be attributed to the different mechanical properties of sample components, in both biological and model systems. Indeed, in the spreading gelled external corona, the evaporation of water causes the solute to be confined into an inexorably smaller volume, until the formation of a rigid network withstanding considerable mechanical stresses. At the air-liquid interface the evaporation surface curves into a set of menisci connecting the particles. The resulting convex curvature leads to a pressure gradient originating from Laplace pressure. It is reasonable to imagine that sponge-like micellar caseins ${ }^{67,68}$ confer a more deformable character to the drying system compared to globular rigid whey proteins, thus influencing the propagation of the drying front most of all when the gel to solid transition is almost completed.

\section{Delay time before cracking and crack dynamics}

Schematizing in a simplistic way the gel phase as a ring thickening during the drying process, in such a dense network the main component of the internal stress is the orthoradial one. ${ }^{62}$ When the maximum capillary pressure is reached in the system (such a value is estimated to be $\approx 5 \gamma / a$, where $v$ is the 
fluid surface tension and $a$ is the average pore size in the network), the orthoradial stresses are so intense to boost the formation of cracks. ${ }^{69,70}$ The occurrence, the development and the final pattern of the cracks strongly depend on the structural properties of the gel and therefore on its components at the molecular scale. ${ }^{13,62,71}$

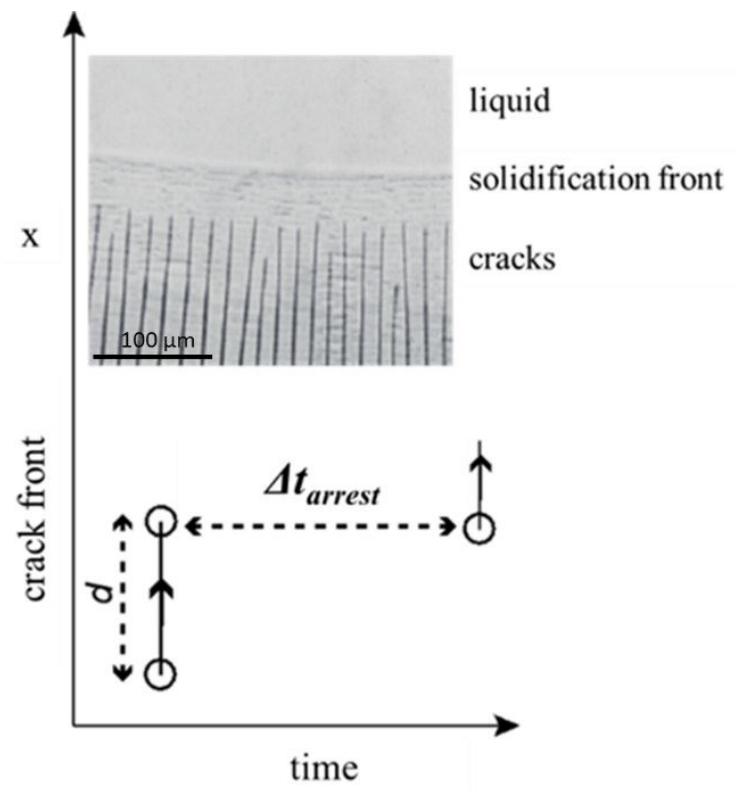

Fig. 5: Sketch showing the discontinuous propagation of cracks: vertical lines indicate the rapid advance of the cracking front, on a distance $d$, until an arrest point (circle); the horizontal dashed line corresponds to a characteristic arrest time, $\Delta$ tarrest, elapsed before the next advance. Image: directional crack pattern in the peripheral solid gel

For this reason, drops of concentrate WPI and NPC solutions led to different cracking dynamics. In the case of sessile drops of WPI, radial cracks progressively invaded the gelled rim of the drying drop (Fig.3c and f), exhibiting a well-defined spacing, as already reported in a previous work of Giorgiutti et al., ${ }^{62}$ and a characteristic staircase shape ${ }^{71,72}$ (inset of Fig.3g). However, contrary to the horizontal solidification front characterized by an almost continuous progress governed by the evaporation rate, the radial crack extremities propagated discontinuously. Indeed, after their occurrence, the cracks showed a sort of cyclic dynamics of propagation. They alternated rapid progresses along distances $d$ towards the center of the droplet and sudden interruptions lasting a characteristic arrest time $\left(\Delta t_{\text {arrest }}\right)$, as sketched in Fig.5. The mean distance $\bar{d}$ between two arrest point is typically equal to $180 \mu \mathrm{m}$ for whey protein droplets. Finally, due to this particular dynamics, crack extremities never reach the horizontal drying front until the complete solidification of the sample. The same evolution was observed during the drying of sessile drops of the WPI associated model system of silica TM50 dispersions (Fig.3h).

As it concerns crack formation in NPC droplets, a quite different behavior was observed. Indeed, the thickening of the gelled external corona towards the center of the drop was accompanied by the absence of cracks (Fig.4a, b and c).
Disordered patterns of cracks invaded the sessile,droplet only once it was almost completely solidified. OThe. 1sarme évolution was observed during the drying of drops of the NPC associated model systems, i.e. TM50+PVP solutions (Fig. 4g).

A statistical analysis on the delay time elapsed before the onset of the first crack $\left(\Delta t_{\text {delay }}\right)$ was carried out to better characterize crack dynamics in both biological and model system droplets
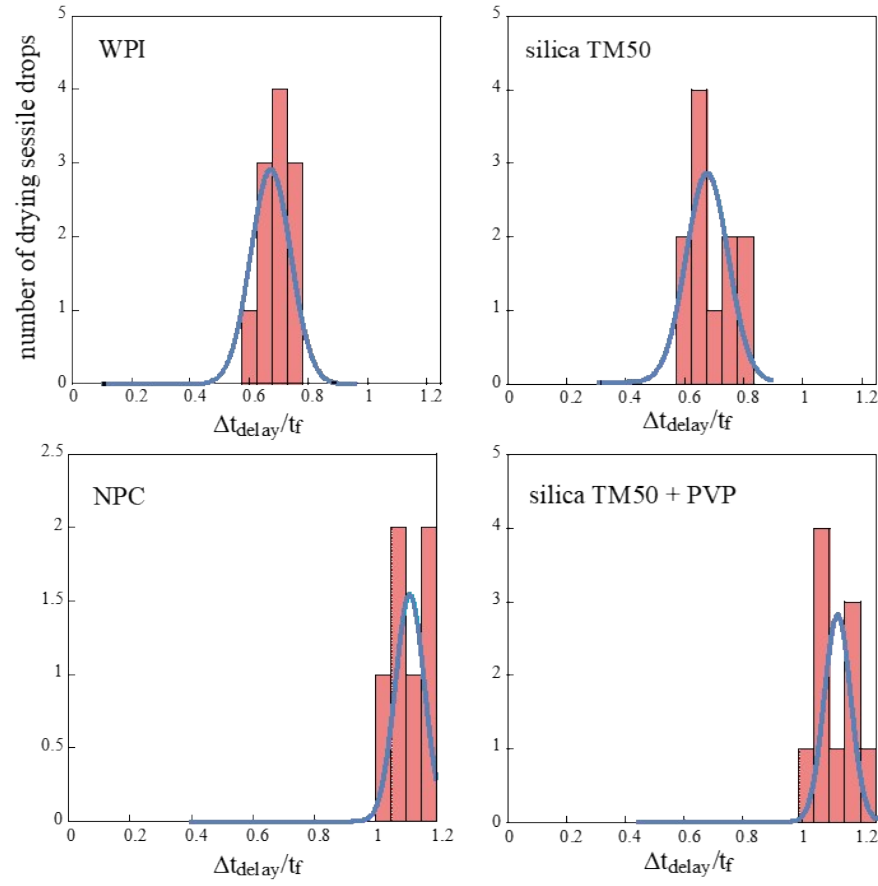

Fig. 6: Statistics on the delay time, $\Delta t_{\text {delay, }}$ elapsed before the formation of the first crack in WPI, NPC and the associated modelled systems over the solidification time $t_{f}$ (time $t=$ 0 corresponds to the drop deposition). The Gaussian distribution is plotted in blue.

(Fig.6). Such measurements confirmed that the first crack reproducibly takes longer to form (almost at the end of the evaporation) in NPC samples (834 $\pm 50 \mathrm{~s})$ with respect to WPI solutions ( $334 \pm 41 \mathrm{~s}$ ), where they develop during the growth of the gelled corona. The same measurements were performed on the two model systems, TM50 (311 $\pm 61 \mathrm{~s}$ ) and TM50+PVP (855 $\pm 40 \mathrm{~s}$ ), further highlighting the significant similar behavior compared to their associated biological solutions.

The systematic characterization of crack development in droplets of whey proteins and casein micelles, and in their corresponding model systems, contribute to corroborate the hypothesis that their mechanical properties at the molecular scale deeply affect the drying process and droplet final shapes. Such possibility is consistent with recent works focusing on the vertical drying front in similar samples and the consequent development of a colloidal skin at the air-liquid interface of the droplets. These studies underlined the formation of a ductile material for NPC and of a brittle layer for WPI. ${ }^{32}$ In particular, as it concerns the deformability enhanced by micellar components, the delayed fracture pointed out in NPC gels can be plausibly approached in the light of a viscoelastic behavior. In a pure linear elastic material, the driving force to propagate a crack is the instantaneous energy release rate: a crack starts to propagate when the energy release rate reaches a critical 
value necessary to create new surfaces. However, in presence of a certain viscoelasticity, a time-dependent irreversible energy dissipating in the solid has to be added to the force balance acting on the system. This dissipative contribution possibly postpones the fracture propagation, leading to a subcritical crack growth, analogous to what reported for polymeric gels. ${ }^{72}$

\section{Mechanical properties of drying films of biological and model systems}

The rheological behavior of dried films of both dairy and model samples was evaluated by indentation tests under constant load. ${ }^{55}$ Such creep measurements allowed estimating the elastic moduli $\left(E_{1}\right.$, $E_{2}$ ) and the viscosity $\eta$ of the material and thus calculating the viscoelastic time $\left(t_{v e}\right)$. In fact, such a characteristic relaxation time is defined by the competition between a viscosity term $(\eta)$ and the elastic modulus $E_{2}$ characterizing the response of a gel to an applied stress $\left(t_{v e}=\eta / E_{2}\right)$. In Fig.7, the penetration depth $(p)$ as a function of time is illustrated for a constant applied force of $30 \mathrm{mN}$. The penetration depth results more significant in NPC and TM50+PVP layers than in WPI and TM50 films, thus further highlighting the enhanced deformability conferred by casein micelles. The values obtained for biological and corresponding model systems are presented in Table 1. Interestingly, the experimental results point out that the viscoelastic relaxation time calculated for dried films of WPI, NPC and model systems is of the same order of the delay time to propagate cracks in drying droplets of the same samples. Therefore, it is reasonable to deduce that fracture dynamics in drying droplets and/or films strictly depend on the intrinsic rheological properties of the colloidal solutions used in this study.

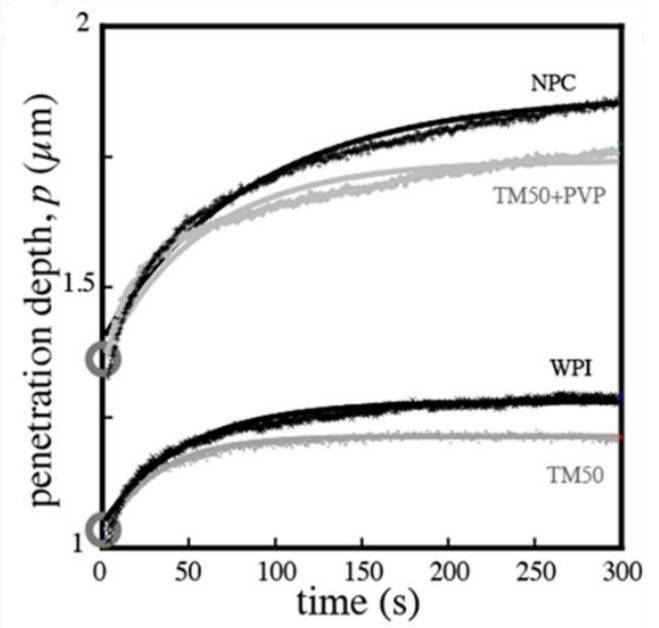

Fig. 7: Measurements of the mechanical properties for WPI, NPC and the associated model systems using indentation testing (CSM Instruments Micro Indentation Tester, MHT). Measurements of the penetration depth, $p$, of the spherical indenter of radius $r=0.25 \mathrm{~mm}$ into the material as a function of time at constant applied force $F_{m}=30 \mathrm{mN}$ ).

The rheological behavior of dried films of both dairy and model samples was evaluated by indentation tests under constant load. ${ }^{55}$ Such creep measurements allowed estimating the elastic moduli $\left(E_{1}, E_{2}\right)$ and the viscosity $\eta$ of the material and thus

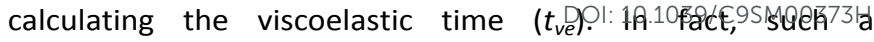
characteristic relaxation time is defined by the competition between a viscosity term $(\eta)$ and the elastic modulus $E_{2}$ characterizing the response of a gel to an applied stress $\left(t_{v e}=\right.$ $\left.\eta / E_{2}\right)$. In Fig.7, the penetration depth $(p)$ as a function of time is illustrated for a constant applied force of $30 \mathrm{mN}$. The penetration depth results more significant in NPC and TM50+PVP layers than in WPI and TM50 films, thus further highlighting the enhanced deformability conferred by casein micelles. The values obtained for biological and corresponding model systems are presented in Table 1 . Interestingly, the experimental results point out that the viscoelastic relaxation time calculated for dried films of WPI, NPC and model systems is of the same order of the delay time to propagate cracks in drying droplets of the same samples. Therefore, it is reasonable to deduce that fracture dynamics in drying droplets and/or films strictly depend on the intrinsic rheological properties of the colloidal solutions used in this study. In this light, beyond a mechanical characterization of biological and model systems, the indentation tests allowed to provide an insight on the microscopic structure of the dry layers. Starting from the estimation of the internal stresses in the drying films, the resulting equation is $E_{1} *\left(t_{v e} / t_{D}\right) \sim 5 \mathrm{~V} / \mathrm{a}$, where $t_{D}$ is the overall drying time of the sample. Therefore, it is possible to compare the pore size in dried layers of WPI and NPC, and in TM50 and TM50+PVP. The values obtained in our experiments suggest an average pore size $(a)$ two times larger in dried networks of WPI compared to NPC layers. This represents a further clue of that in dense phase casein structure confers a higher deformability than whey proteins.

Table 1. Main properties of layers of bio and the associated systems, obtained using indentation testing. Creep measurements, elastic moduli $\left(E_{1}, E_{2}\right)$, viscosity (n). Creep measurements were performed at a constant load $F_{m}=30 \mathrm{mN}$ using indentation testing. The viscoelastic relaxation time, tve, is deduced from the creep parameters.

\begin{tabular}{|c|c|c|c|c|}
\hline & $E_{1}(G P a)$ & $E_{2}(G P a)$ & $\eta\left(G P a^{*} s\right)$ & $\begin{array}{c}t_{v e}=\eta / E_{2} \\
\text { (s) }\end{array}$ \\
\hline$W P I$ & $0.82 \pm 0.08$ & $3.50 \pm 0.08$ & $99 \pm 5$ & $28 \pm 2$ \\
\hline TM50 & $0.85 \pm 0.08$ & $3.20 \pm 0.08$ & $82 \pm 5$ & $26 \pm 2$ \\
\hline$N P C$ & $0.27 \pm 0.08$ & $0.96 \pm 0.08$ & $119 \pm 5$ & $124 \pm 5$ \\
\hline$T M 50+P V P$ & $0.21 \pm 0.08$ & $0.89 \pm 0.08$ & $115 \pm 5$ & $129 \pm 5$ \\
\hline
\end{tabular}

\section{Comparison between biological and colloidal model systems}

The characterization of the mechanical properties of dried layers (see Table 1) underlines, once again, the considerable similarity between dairy and corresponding model systems throughout the evaporation. Some authors have already compared the rheological behavior of milk globular proteins to hard sphere colloidal nanodispersions. ${ }^{73-76}$ Indeed, in a previous study, ${ }^{32}$ we assumed that the brittle plastic characteristics of WPI skin layer could be interpreted by analogy with the concentrated film forming in case of non-interacting colloidal spheres (TM50). This could explain the intrinsic mechanical 
resistance of whey protein networks under compression until reaching a critical crowding condition where the system fractures.

The rheological behavior is quite different in samples of casein micelles, which are dynamic structures, highly hydrated and interacting with the soluble phase. At high concentrations, NPCs can be considered as soft colloids able to deform when undergoing stress, contrary to rigid WPI structures. Thus, the presence of soft components at the molecular scale (NPC) possibly leads to a continuous rearrangement of the system during the drying and to the formation of a ductile skin at the air-liquid interface followed by crack formation only at the end of the process. ${ }^{32}$ Moreover, the similarity in terms of drying behavior between NPC solutions and colloidal silica dispersions (TM50) coated with PVP contributes to obtain more information about casein micelle mechanical behavior, which is still not fully known due to their complex structure. However, such a comparison opens the road to further open questions related to the fact that the TM50+PVP system bears only a layer of soft polymer chains with respect to the highly deformable NPC micelles. The behavior of particle/polymer drying mixtures is much more complex compared to mere colloid dispersions and it has been rarely investigated in the literature. However, a recent study on the evaporation of films of silica particles coated with poly (vinyl alcohol) showed that the final morphology significantly depends on particle/polymer interaction ${ }^{77}$. From our results, it seems plausible that even a thin polymer layer can strongly affect the evaporation process (front propagation, crack development and viscoelastic relaxation). Indeed, an estimation of the thickness of the PVP shell covering the TM50 particles, deduced from the analysis of the TEM images (Fig.8), led to an average value of approximately $8 \mathrm{~nm}$. This result is in accordance with the shell thickness of $\sim 9 \mathrm{~nm}$ of the PVP-coated silica nanoparticles analyzed by $\mathrm{Yu}$ et al. ${ }^{78,79}$. These authors prepared the PVPcoated silica particles by centrifugation and obtained a clearly visible core-shell structure in the TEM images. In this study, the core-shell structure was not clearly visible in the TEM images suggesting an other kind of polymer brush structure as detailed in the review of Zhao and Brittain ${ }^{80}$. To go further, tests were performed by ellipsometry to estimate the thickness of the PVP coating, that is to say the whole structure including the possible PVP core-shell and the outer polydisperse polymer brush.
To this purpose, a Horiba Jobin-Yvon UVISEL spectrometer

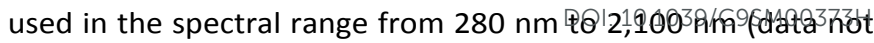
shown). Due to the necessity to investigate a flat regular surface, a silicon wafer with same composition of TM50 was used for the experiments. The wafer was plunged into a reconstituted solution of PVP and, after the evaporation, rinsed and dried. The data analysis was carried out by assuming a multilayer model including a silicon substrate (thickness of $\approx 2$ $\mathrm{nm}$ ) and an outermost polymer layer of a constant refractive index 1.378. Using such hypothesis, the thickness of PVP coating was estimated to be $\approx 65 \mathrm{~nm}$, thus thinner than the average radius of casein micelles. Once again, such measurements were conducted just to obtain the order of magnitude of the PVP coating on TM50 particles and a systematic investigation should be performed to better evaluate: i) chain density and distribution on the surface and ii) the amount of non-anchored polymer remaining in the solvent phase. As it concerns the latter point, in the case of TM50 dispersions, it is reasonable to imagine that polymer chains in excess induce depletion interactions leading to aggregates as suggested by the turbidity
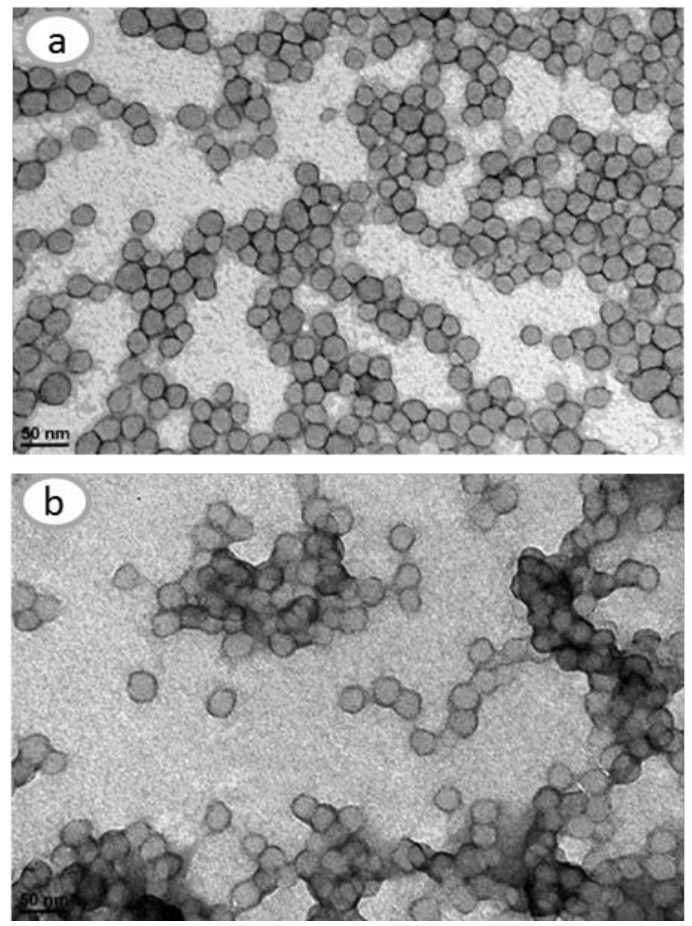

Fig. 8: TEM images of silica nanoparticles (a) and hybrid PVP-silica nanoparticles (b) (Microscope Tecnai G2 Sphera FEI, 200kV).

of the sample (Fig.4d) and by the TEM images of Fig.8.

\section{Conclusions}

Distinct and reproducible experiments were performed on the drying of droplets and films of biological samples (whey proteins and casein micelles) and corresponding colloidal model systems consisting of silica particles (TM50) and polymer-coated silica particles (TM50+PVP), respectively. Due to the significant similarity with dairy samples in terms of drying stages and final crack pattern, model systems, whose structure and behavior 
are more easily deducible, showed to be a potential tool to shed light on the mechanisms of evaporation in such biofluids. In detail, NPC and TM50+PVP dried samples behaved like ductile materials while WPI solutions after evaporation displayed brittle plastic properties. In particular, the study of crack dynamics highlighted a delayed fracture formation in NPC and TM50+PVP drops due to an irreversible portion of dissipated energy, and thus a more pronounced viscoelastic character in soft casein micelles than in rigid globular whey proteins. Interestingly, the results presented on polymer-coated silica particles revealed that even a thin soft layer lining a hard core is able to inhibit or at least to mitigate crack formation. In future works, it would be important to fully characterize the physical properties of PVP coating in wet conditions to better evaluate its impact on the drying stages. Indeed, the average thickness of the polymer layer has been estimated in dry conditions, thus neglecting the possible swelling of PVP chains once immersed in water. However, the almost identical shapes displayed by casein micelle and polymer-coated silica particle samples lead us to hypothesize a similar swelling behavior between dairy and model systems.

Finally, these outcomes allowed us to underline once more that the drying mechanisms (fracture dynamics as well as the final crack morphology) and dried sample rheological behavior are the signature of the mechanical and structural properties of the components at the nano-scale for silica colloids dispersions and for biological colloid solutions. Therefore, this work opens the road to further theoretical and experimental studies taking advantage of the better knowledge about model colloids to explain the behavior of complex biological systems. Moreover, shedding light on the physics of the evaporation of dairy single droplets is potentially crucial for industrial applications, especially in the control of spray drying. In fact, the prediction of mechanical and structural characteristics of droplets of biological colloids using colloidal model systems would provide a powerful tool to improve and control the structure of food.

\section{Conflicts of interest}

There are no conflicts to declare.

\section{Acknowledgements}

The authors thank Denis Morineau from the Institute of Physics of Rennes for the ellipsometry measurements.

\section{References}

1 W. E. Ranz and, W. R. Marshall, Chem. Eng. Prog., 1952, 48, 141-146.

2 T. M. Elsayed, D. A. Wallack and C. J. King, Ind. Eng. Chem., 1990, 29, 2346-2354.

3 L. Pauchard and Y. Couder, Europhys. Letters, 2004, 66, 667673.

4 R. Vehring, W. R. Foss and D. Lechuga-Ballesteros, J. Aerosol Sci., 2007, 38, 728-746.
5 H. Y. Erbil, Adv. Colloid Interface Sci., 2012 170 170 67$86 . \quad$ DOI: 10.1039/C9SMO0373H

6 M. A. Hampton, T. A. H. Nguyen, A. V. Nguyen, Z. P. Xu, L. Huang and V. Rudolph, J. Colloid Interface Sci., 2012, 377, 456462.

7 A. G. Marín, H. Gelderblom, A. Susarrey-Arce, A. van Houselt, L. Lefferts, J. G. E. Gardeniers, D. Lohse and J. H. Snoeijer, Proc. Nat. Acad. Sci., 2012, 109, 16455-16458.

8 Y. S. Yu, Z. Q. Wang and Y. P. Zhao, J. Colloid Interface Sci., 2012, 365, 254-259.

9 J. Perdana, M. Fox, M. Schutyser and R. Boom, Food Bioprocess Technol, 2013, 6, 964-977.

10 J. Mangel and E. Baer, Chem. Engi. Sci., 1962, 17, 705-706.

11 R. D. Deegan, O. Bakajin, T. F. Dupont, G. Huber, S. R. Nagel and T. A. Witten, Nature, 1997, 389, 827-829.

12 L. Goehring, A. Nakahara, T. Dutta, S. Kitsunezaki and S. Tarafdar, Desiccation Cracks and their Patterns: Formation and Modelling in Science and Nature, Weinheim: Wiley-VCH, 2015.

13 L. Pauchard, F. Elias, P. Boltenhagen, A. Cebers and J.C. Bacri, Phys. Rev. E, 2008, 77, 021402/1-021402/9.

14 V. R. Dugyala, H. Lama, D. K. Satapathy and M. G. Basavaraj, Sci Rep., 2016, 6: 30708.

15 Y. Y. Tarasevich, I. V. Vodolazskaya and O. P. Isakova, Colloid Polym. Sci., 2011, 289, 1015-1023.

16 T. Yakhno, V. Kazakov, A. SaninO. Shaposhnikova and A. Chernov, Technical Physics, 2007, 52, 515-520.

17 T. Yakhno, J. Colloid Interface Sci., 2008, 318, 225-230.

18 W. Bou Zeid and D. Brutin, Colloids Surf., A, 2013, 430, 1-7.

19 B. Sobac and D. Brutin, Colloids Surf. A, 2014, 448, 34-44.

20 R. Chen, L. Zhang, D. Zang and W. Shen, J. Mater. Chem. B, 2017, 5, 8991-8998.

21 L. Lanotte, D. Laux, B. Charlot and M. Abkarian, Phys. Rev. E, 2017, 96, 053114.

22 Y. Y. Tarasevich, Physics - Uspekhi, 2004, 47, 717-728.

23 C. Annarelli, J. Fornazero, J. Bert, J. et al. Eur. Phys. J. E, 2001, 5, 599-603.

24 K. Sefiane, J. Bionic Eng., 2010, 7, S82-S93.

25 H. M. Gorr, J. M. Zueger, D. R. McAdams, J. A. Barnard, Colloids Surf., $B, 2013,103,59-66$.

26 R. Chen, L. Zhang, D. Zang and W. Shen, M.M. Rahman, A.M. Asiri (Eds.), Adv. Colloid Sci, InTech, 2016, Chapter 1, 3-25.

27 D. Brutin and V. Starov, Chem. Soc. Rev., 2018, 47, 558-585.

28 F. Giorgiutti-Dauphiné and L. Pauchard, Eur. Phys. J. E., 2018, 41: 32.

29 P. Bacchin, D. Brutin, A. Davaille, Erika Di Giuseppe, X. Dong Chen, I. Gergianakis, F. Giorgiutti-Dauphiné, L. Goehring, Y. Hallez, R. Heyd, R. Jeantet, C. Le Floch-Fouéré, M. Meireles, E. Mittelstaedt, C. Nicloux, L. Pauchard and M-L. Saboungi, Eur. Phys. J. E, 2018, 41: 94.

30 M. Parsa, S. Harmand and K. Sefiane, Adv. Colloid Interface Sci., 2018, 254, 22-47.

31 C. Sadek, H. Li, P. Schuck, Y. Fallourd, N. Pradeau, C. Le FlochFouéré and R. Jeantet, Drying Technology, 2014, 32, 15401551.

32 C. Sadek, L. Pauchard, P. Schuck, Y. Fallourd, N. Pradeau, C. Le Floch-Fouéré and R. Jeantet, Food Hydrocolloids, 2015, 48, 816.

33 C. Sadek, P. Schuck, Y. Fallourd, N. Pradeau, R. Jeantet and C. Le Floch-Fouéré, Food Hydrocolloids, 2016, 52, 161-166.

34 P. Walstra, J. T. M. Wouters and T. J. Geurts, Eds.; Dairy Science and Technology, 2nd ed.; CRC/Taylor \& Francis: Boca Raton, FL, 2006, Chapter 2, 76-79.

35 P. F. Fox and A. Brodkorb, Int. Dairy J., 2008, 18, 677-684.

36 P. Walstra, Int. Dairy J., 1999, 9, 189-192.

37 D. S. Horne, Curr. Opin. Colloid Interface Sci., 2006, 11, 148153.

38 D. G. Dalgleish, Soft Matter, 2011, 7, 2265-2272. 
39 C. G. de Kruif, T. Huppertz, V. S. Urban and A. V. Petukhov, Adv. Colloid Interface Sci., 2012, 171-172, 36-52.

40 B. Ingham, B. Smialowska, G. D. Erlangga, L. Matia-Merino, N. M. Kirby, C. Wang, R. G. Haverkamp and A. J. Carr, Soft Matter, 12 (2016), 6937-6953.

41 C. Sadek, H. Tabuteau, P. Schuck, Y. Fallourd, N. Pradeau, C. Le Floch-Fouéré and R. Jeantet, Langmuir, 2013, 29, 1560615613.

42 R. Iler, The Chemistry of Silica: Solubility, Polymerization, Colloid and Surface Properties and Biochemistry of Silica, Wiley Interscience, 1979.

43 S. K. Parida, S. Dash, S. Patel and B. K. Mishra, Adv. Colloid Interface Sci., 2006, 121, 77-110.

44 F. Lafuma, K. Wong and B. Cabane, J. Colloid Interface Sci., 1991, 143, 9-21.

45 Y. Otsubo, Langmuir, 1990, 6, 114-118.

46 K. Wong, P. Lixon, F. Lafuma, P. Lindner, O. Aguerre Charriol and B. Cabane, J. Colloid Interface Sci., 1992, 153, 55-72.

47 B. Cabane, K. Wong, P. Lindner and F. Lafuma, J. Rheol., 1997, 41, 531-547.

48 P. llekti, Ph.D. thesis, Université Pierre et Marie Curie, 2000.

49 M. Liu, Q. Chen, S. Wang, L. Bai, M. Sang, W. Jiang, S. Xuan and X. Gong, J. Nanopart. Res., 2017, 19:234.

50 F. Boulogne, F. Giorgiutti-Dauphiné and L. Pauchard, Soft Matter, 2015, 11, $102-108$

51 M. A. Cohen Stuart, G. J. Fleer, and B. H. Bijsterbosch, J. Colloid Interface Sci., 1982a, 90, 310-320.

52 M. A. Cohen Stuart, G. J. Fleer, and B. H. Bijsterbosch, J. Colloid Interface Sci., 1982b, 90, 321-334.

53 M. A. Cohen Stuart, G. J. Fleer, and J. M. H. M. Scheutjens, J. Colloid Interface Sci., 1984, 97, 526-535.

54 L. Pauchard, F. Parisse and C. Allain, Phys. Rev. E, 1999, 59, 3737.

55 J. Malzbender, J. M. J. den Toonder, A. R. Balkenende, and G. de With, Mater. Sci. Eng., 2002, R 36, 47-103.

56 C. Fischer-Cripps, Nanoindentation, Springer, New-York, 2011.

57 K. R. Parmar, S. R. Shah and N. R. Sheth, J. Pharm. Innov., 2011, $6,107-114$

58 K. Namekawa, A. Kaneko, K. Sakai, S. Kunikata and M. Matsuda, J. Artif. Organs., 2011, 14, 52-57.

59 M. El-Badry and M. Fathy, Drug Dev. Ind. Pharm., 2006, 32 141-150.

60 G. Van den Mooter, P. Augustijns, N. Blaton and R. Kinget, Int. J. Pharm., 1998, 164, 67-80.

61 K. M. Koczkur, S. Mourdikoudis, L. Polavarapu and, S. E. Skrabalak, Dalton trans., 2015, 44, 17883-17905.

62 F. Giorgiutti and L. Pauchard, Eur. Phys. J. E, 2014, 37:39.

63 Y. J. Zhang, Z. T. Liu, D. Y. Zang, Y. M. Qian and K. J. Lin, Sci. China-Phys. Mech. Astron., 2013, 56, 1712-1718.

64 L. Pauchard, B. Abou and K. Sekimoto, Langmuir, 2009, 25, 6672-6677.

65 M. Nassar, A. Gromer, F. Thalmann, P. Hébraud and Y. Holl, J. Colloid Interface Sci., 2018, 511, 424-433.

66 R.D. Deegan, Phys. Rev. E, 2000, 61, 475-485.

67 A. Bouchoux, G. Gésan-Guiziou, J. Pérez and B. Cabane, Biophys. J., 2010, 99, 3754-3762.

68 A. Bouchoux, J. Ventureira, G. Gésan-Guiziou, F. GarnierLambrouin, P. Qu, C. Pasquier, S. Pézennec, R. Schweins and B. Cabane, Soft Matter, 2015, 11, 389-399.

69 E. R. Dufresne, E. I. Corwin, N. A. Greenblatt, J. Ashmore, D. Y. Wang, A. D. Dinsmore, J. X. Cheng, X. S. Xie, J. W. Hutchinson and D. A. Weitz, Phys. Rev. Lett., 2003, 91, 224501

70 W. P. Lee and A. F. Routh, Langmuir, 2004, 20, 9885-9888.

71 A. L. R. Sibrant and L. Pauchard, EPL, 2016, 116, 49002.

72 X. Wang and W. Hong, Soft Matter, 2012, 8, 8171.

73 G. J. Brownsey, T. R. Noel, R. Parker and S. G. Ring, Biophys. J., 2003, 85, 3943-3950.
74 S. M. Loveday, L. K. Creamer, H. Singh and M. A. Rao J. Food Sci., 2007, 72, 101-107. DOl. 10.1039/C9SM00373H

75 R. Parker, T. R. Noel, G. J. Brownsey, K. Laos and S. G. Ring, Biophys. J., 2005, 89, 1227-1236.

76 T. Nicolai and D. Durand, Curr. Opin. Colloid Interface Sci., 2007, 12, 23-28.

77 S. Kim, K. Hyun, B. Struth, K. H. Ahn and C. Clasen, Macromolecules, 2016, 49, 9068-9079.

78 K. Yu, H. Zhang, C. Hodges, S. Biggs, Z. Xu, O. J. Cayre and D. Harbottle, Langmuir, 2017, 33, 6528-6539.

79 K. Yu, H. Zhang, C. Hodges, S. Biggs, Z. Xu, O. J. Cayre and D. Harbottle, J. Colloid Interface Sci., 2018, 527, 346-355.

80 B. Zhao and W. J. Brittain, Prog. Polym. Sci., 2000, 25, 677710. 

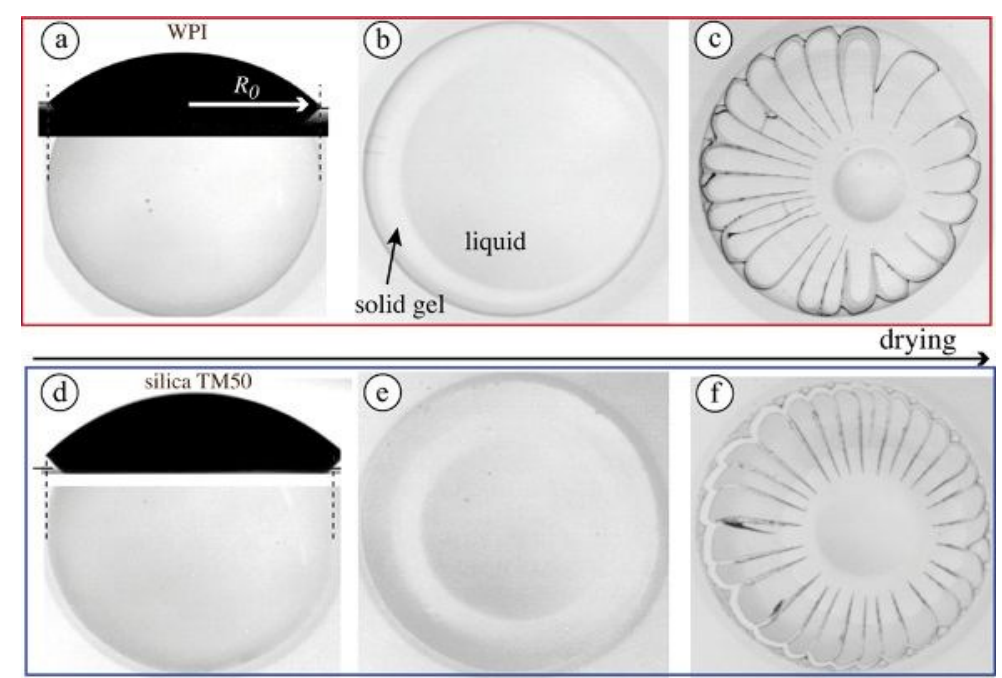

Impact of solute properties on the morphological characteristics of evaporating droplets investigated through the analysis of drying stages and final crack pattern of biological samples (WPI, Whey Protein) and model silica dispersions (TM50). 